\title{
ASSESSMENT OF THE ECOTOXICITY OF NANOPLASTICS
}

\author{
Nóra Kováts*1, BeTtina ECK-VARANKA ${ }^{1}$, ZSÓFIa BÉKÉSSY ${ }^{1}$, Dorina DIÓSI ${ }^{1}$, KatAlin \\ HUBAI $^{1}$, AND JÁNOS KORPONAI ${ }^{2}$ \\ ${ }^{1}$ Institute of Environmental Sciences, University of Pannonia, 8200 Veszprém, Egyetem u. 10, HUNGARY \\ ${ }^{2}$ Department of Environmental Science, Sapientia Hungarian University of Transylvania, 400193 \\ Cluj-Napoca, Calea Turzii 4, ROMANIA
}

\begin{abstract}
The presence of micro- and nanoplastics in aquatic environments (including freshwater and marine ecosystems as well as their sediments) is becoming an increasingly serious problem worldwide. A wide range of studies have addressed the ecological effects these particles pose on biota. The main exposure pathway are food chains, e.g. under laboratory conditions these particles accumulate in the brain tissues of fish that feed on zooplankton causing brain damage. These studies, however, report mainly on the physical effects. In order to establish actual ecotoxicological effects, nanoplastics (50 nm in diameter) were assessed using the Vibrio fischeri bioluminescence inhibition bioassay (VFBIA). Our results showed that even environmentally relevant concentrations might trigger ecotoxicological effects. This study can be considered to be a first screening, however, results indicate the need for more complex testing on a battery of aquatic test organisms.
\end{abstract}

Keywords: nanoplastic; ecotoxicity; Vibrio fischeri; kinetic assay

\section{Introduction}

Aquatic environments contaminated by plastic litter are an emerging problem. Remote, pristine mountainous areas are even contaminated by atmospheric microplastic deposition [1]. Polymer particles $<5 \mathrm{~mm}$ in diameter are defined as microplastics (MP) and may be derived directly from the use of industrial pellets or indirectly from the degradation and fragmentation of plastic particles [2]. Polystyrene was proven to degrade into microand nanoplastics under laboratory conditions [3]. High levels of contamination have been reported in both marine and freshwater habitats $[4,5]$. Micro- and nanoplastics (NP) can float freely in bodies of water or be deposited as sediments.

The highest risk associated with these particles is their ingestion, which occurs at different levels in the aquatic food chain. Jabeen et al. [6], for example, listed approximately 150 different fish species where ingestion and accumulation have been reported. Particles can also progress upwards in the trophic levels of the food chain, i.e. fish can be exposed to the ingestion of zooplankton which is not able to discriminate between different food sources and consumes micro- and nanoplastics [7]. An experimental study showed that in fish exposed to NPs via the food chain, these particles caused brain damage and behavioural disorders as a result of accumulation in

\footnotetext{
*Correspondence: kovats@almos.uni-pannon.hu
}

brain tissues [8]. Biomagnification may also affect food safety and human health, though certain knowledge gaps exist in this field [9].

Ingestion may actually lead to starvation and eventually the impairment of their physical condition. Under laboratory conditions, Daphnia magna exposed to polystyrene nanoparticles (PS-NP) exhibited reduced body size and severe alterations in terms of reproduction [10]. D. magna is a widely studied species due to its key role in the aquatic food chain. It was shown to ingest nano- and microplastics ( $20 \mathrm{~nm}$ to $70 \mu \mathrm{m}$ in diameter) from water [11]. In a laboratory study by Mattsson et al. [8], particles $52 \mathrm{~nm}$ in diameter elucidated the most severe effects. Cui et al. [12] exposed D. galeata to PSNPs ( $5 \mathrm{mg} / 1,52 \mathrm{~nm}$ in diameter) and detected a significant mortality rate after 2 days of exposure until the end of the study which lasted 5 days. Although a standard ecotoxicological test was conducted in this case, the mechanisms of mortality are still unclear: physical contact might have led to a reduction in the survival rate.

In general, most ecotoxicological studies have used relatively high concentrations. Manfra et al. [13] investigated the impact of green fluorescently labeled carboxylated polystyrene nanoparticles of $40 \mathrm{~nm}$ in diameter with various surface charges on the marine rotifer Brachionus plicatilis. It was found that anionic PS-NPs did not elucidate mortality within the range of concentrations tested $(0-50 \mu \mathrm{g} / \mathrm{ml})$, while cationic PS-NPs caused mortality at 
concentrations $\geq 2.5 \mu \mathrm{g} / \mathrm{ml}$. Changes in oxidative stress enzymes were detected within the concentration range of $10-20 \mu \mathrm{g} / \mathrm{ml}$ in different organisms, e.g. the rotifer Brachionus koreanus and the marine copepod Paracyclopina nana [14]. The same concentration, $10 \mu \mathrm{g} / \mathrm{ml}$, was reported to cause $40 \%$ growth inhibition in the green microalga Dunaliella tertiolecta [15].

In order to distinguish real (eco)toxicological effects from physical damage, a test based on the bioluminescence inhibition of the marine bacterium Vibrio fischeri was selected. The species has been reclassified as Aliivibrio fischeri [16], however, as most standards and even recent papers from the literature still use the name $V$. fischeri, it will be used hereinafter.

Bioluminescence is regulated by the enzyme system NAD(P)H:FMN oxidoreductase-luciferase. In toxic environments, enzyme inhibition is reflected by a rapid decrease in the luminous emittance of the bacterium. The reduction in light intensity is easy to measure as it is proportional to the strength of the toxicant, therefore, provides a quantifiable endpoint. This test has been used in various environmental matrices [17-19].

Lappalainen et al. [20,21] developed a special version of the test which was later standardised (ISO 21338:2010: Water quality - Kinetic determination of the inhibitory effects of sediment, other solids and coloured samples on the light emission of Vibrio fischeri (kinetic luminescent bacteria test)) in which bacteria are kept in suspension in direct contact with potentially toxic solid particles. Luminescence readings were taken when the test commenced and the light intensity continuously monitored over the first 30 secs after the sample had been mixed with the bacteria. The light output pattern, therefore, might already provide some indication of the expected toxicity of the sample [22]. The light intensity was measured once more after the pre-set exposure time $(5,15$ or 30 mins as per standard). Toxicity values are normally expressed as EC50 and EC20, i.e. concentrations causing luminescence inhibitions of 50 and $20 \%$ in this assay, respectively.

\section{Materials and Methods}

In our experiments, the Ascent luminometer (Flash system, marketed by Aboatox, Finland) was used. A suspension of the test bacteria (NRRL B-11177) was prepared in accordance with manufacturer instructions (Hach Lange $\mathrm{GmbH})$.

Polystyrene particles with a nominal diameter of 50 nm were used as a sample (supplier Thermo Fisher Scientific). As no comparative data were available on the potentially toxic concentration, a range-finding concentration series was set [23]. Three initial sample concentrations were selected $(1 \mathrm{~g} / \mathrm{l}, 1 \mu \mathrm{g} / \mathrm{l}$ and $1 \mathrm{ng} / \mathrm{l})$, which were further diluted, the number of dilutions was 11 (the number of concentrations the 96-multiwell plate permits) and the dilution ratio $1: 2$.
Table 1: The measured EC20 values of the polystyrene nanoparticles.

\begin{tabular}{llll}
\hline Concentration & $1 \mathrm{~g} / \mathrm{l}$ & $1 \mu \mathrm{g} / \mathrm{l}$ & $1 \mathrm{ng} / \mathrm{l}$ \\
\hline $\mathrm{EC} 20$ & 5.2 & 17.31 & 30.51 \\
\hline
\end{tabular}

The Vibrio fischeri strain NRRL B-11177 was reconstituted by adding the contents of one vial of $+4{ }^{\circ} \mathrm{C} 1243$ 551 Reagent Diluent. The reconstituted reagent was equilibrated at $+4{ }^{\circ} \mathrm{C}$ for $30 \mathrm{~min}$. Then the reagent was stabilised at $+15{ }^{\circ} \mathrm{C}$ for 30 mins before being pipetted into the wells.

Luminescence readings were taken when the test commenced, Time0, and after the pre-set exposure time of 30 mins, Time30. The luminescence inhibition of each sample was calculated as follows:

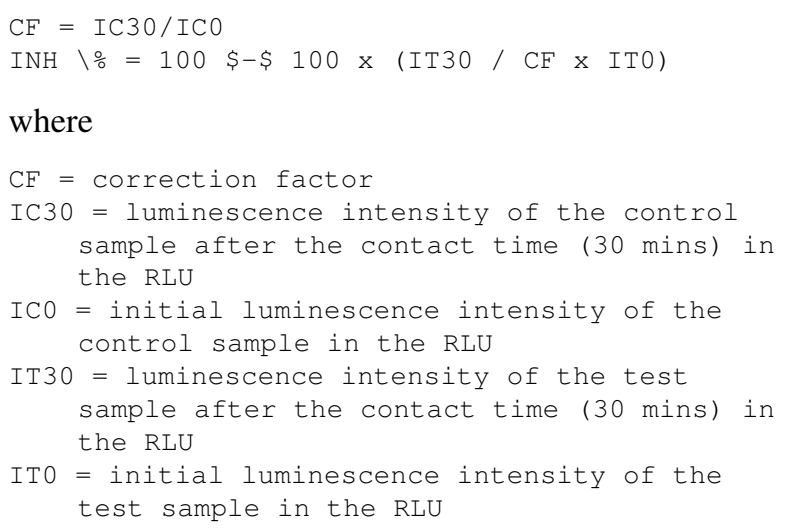

EC2 0 values were calculated using the Ascent software, also developed by Aboatox Oy.

\section{Results and Discussion}

Table 1 shows the ecotoxicity expressed in EC20, i.e. the calculated concentration of the sample that caused $20 \%$ bioluminescence inhibition. Fig. 1 illustrates the bioluminescence inhibition during the first 30 secs for the samples of $1 \mathrm{~g} / \mathrm{l}$ and $1 \mathrm{ng} / \mathrm{l}$ in concentration.

$\mathrm{EC} 20$ (or in some cases, EC10) are considered thresholds for the estimation of the lowest observed effective concentration [24], i.e. the sample is normally considered (eco)toxic if the elucidated effect exceeds $20 \%$.

These results show that the $V$. fischeri bioassay detected a measurable degree of toxicity even at a concentration of $1 \mathrm{ng} / \mathrm{l}$. Booth et al. [25] used the non-kinetic version of this bioassay (Microtox $\left.{ }^{\circledR}\right)$, however, in their study, the calculated toxic concentration exceeded the range of concentrations studied $(0.001-1000 \mathrm{mg} / \mathrm{l})$. The same negative effect was reported by Casado et al. [26]. The higher degree of (detectable) toxicity in our study might be explained by the differences in the test system used. While Microtox ${ }^{\circledR}$ is a non-kinetic test, the Flash system (Ascent luminometer) was especially developed to test the toxicity of different suspensions or samples containing solid particles. The Ascent luminometer uses a 96-multiwell microplate. A specific feature of it is that 
(a)

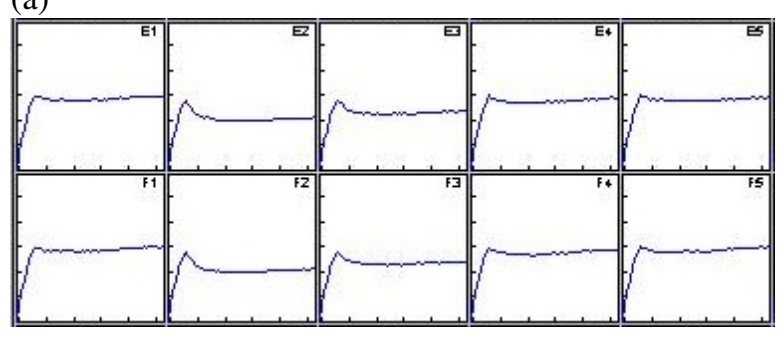

(b)

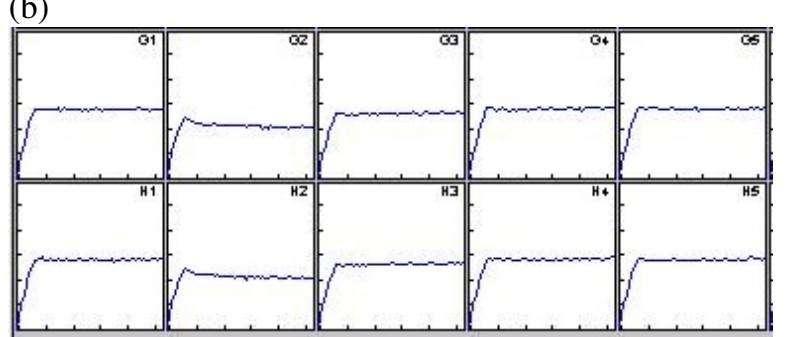

Figure 1: Kinetic diagram of the $1 \mathrm{~g} / \mathrm{l}$ (a) and $1 \mathrm{ng} / \mathrm{l}$ (b) samples. The light output is recorded over the first $30 \mathrm{sec}-$ onds. After the peak, toxicity causes a rapid reduction in the light output, on the other hand, it remains constant during the control. The two columns show the two replicates. E1-F1/G1-H1 (left): control. E2-F2/G2-H2 (right): sample, maximum concentration.

during luminescence readings, the microplate is continuously shaken by the instrument, resulting in the resuspension of particles.

According to our results, environmentally relevant concentrations might already pose ecotoxic effects. Actual environmental concentrations are relatively difficult to compare and assess, mostly due to difficulties in sampling and the lack of standardized sampling methodologies $[27,28]$. Indicative data are available: e.g. microplastic concentrations of $0.4-34 \mathrm{ng} / \mathrm{l}$ in bodies of freshwater in the USA [29] or $0.51 \mathrm{mg} / \mathrm{l}$ in marine environments [10].

However, in real-world environments, even higher levels of toxicity can be expected as particles might absorb organic pollutants from the surrounding water [30], including highly toxic pesticides or polychlorinated biphenyls (PCBs) [31]. Though their bioavailability is still questionable [32], Batel et al. [33] conducted a laboratory study on microplastics and one polycyclic aromatic hydrocarbon (PAH), benzo[a]pyrene (BaP). It was demonstrated that $\mathrm{BaP}$ adsorbed on microplastics and was transferred via an artificial food chain. These particles might also possess inherent toxicity due to the use of additives during manufacturing processes [34].

\section{Conclusions}

It is a well-known paradigm in ecotoxicology that the sensitivity of different test organisms to a particular chemical varies, therefore, the V. fischeri test can be regarded as a first screening. The bioluminescence inhibi- tion assay is an acute test that uses a maximum exposure of only 30 minutes. Naturally, chronic effects cannot be extrapolated from these results. However, the fact that the tested nanoplastics have already elucidated ecotoxicological effects in environmentally relevant concentrations emphasises the need for more complex ecotoxicological testing involving a properly selected battery of test organisms. In addition to widely used aquatic test organisms such as the aforementioned Daphnia magna, an ideal candidate could be the Caenorhabditis elegans test. It is a standardised bioassay using a sediment-dwelling, widely distributed nematode. However, in order to distinguish physical damage from toxic effects, the measurement of changes in oxidative stress enzymes can be useful no matter which test organism is applied.

\section{Acknowledgement}

This work was funded by the BIONANO_GINOP-2.3.215-2016-00017 project.

\section{REFERENCES}

[1] Allen, S.; Allen, D.; Phoenix, V.R.; Le Roux, G.; Jiménez, P.D.; Simonneau, A.; Binet, S.; Galop, D.: Atmospheric transport and deposition of microplastics in a remote mountain catchment, Nature Geoscience 2019, 12(5), 339-344 DOI: 10.1038/s41561-0190335-5

[2] Mintenig, S.M.; Dris, R.; Imhof, H.; Sanchez, W.; Gasperi, J.; Galgani, F.; Tassin, B.; Laforsch, C.: Beyond the ocean: Contamination of freshwater ecosystems with (micro-)plastic particles, Environ. Chem. 2015, 12(5) 539-550 DOI: 10.1071/en14172

[3] Lambert, S.; Wagner, M.: Characterisation of nanoplastics during the degradation of polystyrene, Chemosphere 2016, 145 265-268 DOI: 10.1016/j.chemosphere.2015.11.078

[4] Cole, M.; Lindeque, P.; Halsband, C.; Galloway, T.S.: Microplastics as contaminants in the marine environment: a review, Mar. Pollut. Bull. 2011, 62 2588-2597 DOI: 10.1016/j.marpolbul.2011.09.025

[5] Dris, R.; Gasperi, J.; Rocher, V.; Saad, M.; Renault, N.; Tassin, B.: Microplastic contamination in an urban area: a case study in Greater Paris, Environ. Chem. 2015 12(5), 592-599 DOI: 10.1071/en14167

[6] Jabeen, K.; Su, L.; Li, J.; Yang, D.; Tong, C.; Mu, J.; Shi, H.: Microplastics and mesoplastics in fish from coastal and fresh waters of China, Environ. Pollut. 2017, 221, 141-149 DOI: 10.1016/j.envpol.2016.11.055

[7] Chae, Y.; An, Y.-J.: Effects of micro- and nanoplastics on aquatic ecosystems: Current research trends and perspectives, Mar. Pollut. Bull. 2017, 124(2), 624-632 DOI: 10.1016/j.marpolbul.2017.01.070

[8] Mattsson, K.; Johnson, E.V.; Malmendal, A.; Linse, S.; Hansson, L.-A.; Cedervall, T.: Brain damage and behavioural disorders in fish induced by plastic nanoparticles delivered through the food chain, Sci. Rep. 2017, 7(1), 11452 DOI: 10.1038/s41598-017-10813-0 
[9] Barboza, L.G.A.; Vethaak, A.D.; Lavorante, B.R.B.O.; Lundebye, A.-K.; Guilhermino, L.: Marine microplastic debris: An emerging issue for food security, food safety and human health, Mar. Pollut. Bull. 2018, 133, 336-348 DOI: 10.1016/j.marpolbul.2018.05.047

[10] Besseling, E.; Wang, B.; Lürling, M.; Koelmans, A.A.: Nanoplastic Affects Growth of $S$. obliquus and Reproduction of D. magna, Environ. Sci. Technol. 2014, 48(20), 12336-12343 DOI: 10.1021/es503001d

[11] Rosenkranz, P.; Chaudhry, Q.; Stone, V; Fernandes, T.F.: A comparison of nanoparticle and fine particle uptake by Daphnia magna, Environ. Toxicol. Chem. 2009, 28(10), 2142-2149 DOI: 10.1897/08-559.1

[12] Cui, R.; Kim, S.W.; An, Y.-J.: Polystyrene nanoplastics inhibit reproduction and induce abnormal embryonic development in the freshwater crustacean Daphnia galeata, Sci. Rep. 2017, 7(1), 12095 DOI: 10.1038/s41598-017-12299-2

[13] Manfra, L.; Rotini, A.; Bergami, E.; Grassi, G.; Faleri, C.; Corsi, I.: Comparative ecotoxicity of polystyrene nanoparticles in natural seawater and reconstituted seawater using the rotifer Brachionus plicatilis, Ecotoxicol. Environ. Saf. 2017, 145, 557563 DOI: 10.1016/j.ecoenv.2017.07.068

[14] Prokić, M.D.; Radovanović, T.B.; Gavrić, J.P.; Faggio, C.: Ecotoxicological effects of microplastics: Examination of biomarkers, current state and future perspectives, Trends. Analyt. Chem. 2019, 111, 3746 DOI: 10.1016/j.trac.2018.12.001

[15] Gambardella, C.; Morgana, S.; Bramini, M.; Rotini, A.; Manfra, L.; Migliore, L.; Piazza, V.; Garaventa, F.; Faimali, M.: Ecotoxicological effects of polystyrene microbeads in a battery of marine organisms belonging to different trophic levels, Mar. Environ. Res. 2018, 141, 313-321 DOI: 10.1016/j.marenvres.2018.09.023

[16] Urbanczyk, H.; Ast, J.; Higgins, M.J.; Carson, J.; Dunlap, P.V.: Reclassification of Vibrio fischeri, Vibrio logei, Vibrio salmonicida and Vibrio wodanis as Alivibrio fischeri gen. nov., comb. nov., Aliivibrio logei comb. nov., Aliivibrio salmonicida comb. nov. and Aliivibrio wodanis comb. nov., Int. J. Syst. Evol. Microbiol. 2007, 57(12), 2823-2829 DOI: 10.1099/ijs.0.65081-0

[17] Girotti, S.; Ferri, E.N.; Fumo, M.G.; Maiolini, E.: Monitoring of environmental pollutants by bioluminescent bacteria, Anal. Chim. Acta 2008, 608(1), 229 DOI: 10.1016/j.aca.2007.12.008

[18] Ma, X.Y.; Wang, X.C.; Ngo, H.H.; Guo, W.; Wu, M.N.; Wang, N.: Bioassay based luminescent bacteria: Interferences, improvements, and applications, Sci. Total Environ. 2014, 468-469, 1-11 DOI: 10.1016/j.scitotenv.2013.08.028

[19] Abbas, M.; Adil, M.; Ehtisham-ul-Haque, S.; Munir, B.; Yameen, B.; Ghaffar, A. et al.: Vibrio fischeri bioluminescence inhibition assay for ecotoxi- city assessment: A review, Sci. Total Environ. 2018, 626, 1295-1309 DOI: 10.1016/j.scitotenv.2018.01.066

[20] Lappalainen, J.; Juvonen, R.; Vaajasaari, K.; Karp, M.: A new flash method for measuring the toxicity of solid and colored samples, Chemosphere 1999, 38(5), 1069-1083 DOI: 10.1016/s0045-6535(98)00352-x

[21] Lappalainen, J.; Juvonen, R.; Nurmi, J.; Karp, M.: Automated color correction method for Vibrio fischeri toxicity test. Comparison of standard and kinetic assays, Chemosphere 2001, 45(4-5), 635-641 DOI: 10.1016/s0045-6535(00)00579-8

[22] Mortimer, M.; Kasemets, K.; Heinlaan, M.; Kurvet, I.; Kahru, A.: High throughput kinetic bioluminescence inhibition assay for study of toxic effects of nanoparticles, Toxicol. in Vitro 2008, 22(5), 1412 1417 DOI: $10.1016 /$ j.tiv.2008.02.011

[23] USEPA (2000) Method Guidance and Recommendations for Whole Effluent Toxicity (WET) Testing (40 CFR Part 136). EPA 821-B-00-004. U.S. Environmental Protection Agency, Office of Water

[24] Ventura, S.P.M.; Silva, F.A.; Gonçalves, A.M.M.; Pereira, J.P.; Gonçalves, J.P.; Coutinho, J.A.P.: Ecotoxicity analysis of cholinium-based ionic liquids to Vibrio fischeri marine bacteria, Ecotoxicol. Environ. Saf. 2014, 102, 48-54 DOI: 10.1016/j.ecoenv.2014.01.003

[25] Booth, A.M.; Hansen, B.H.; Frenzel, M.; Johnsen, H.; Altin, D.: Uptake and Toxicity of Methylmethacrylate-Based Nanoplastic Particles in Aquatic Organisms, Environ. Toxicol. Chem. 2016, 35(7), 1641-1649 DOI: 10.1002/etc.3076

[26] Casado, M.P.; Macken, A.; Byrne, H.J.: Ecotoxicological assessment of silica and polystyrene nanoparticles assessed by a multitrophic test battery, Environ. Int. 2013, 51, 97-105 DOI: 10.1016/j.envint.2012.11.001

[27] Rocha-Santos, T.; Duarte, A.C.: A critical overview of the analytical approaches to the occurrence, the fate and the behavior of microplastics in the environment, Trends Analyt. Chem. 2015, 65, 47-53 DOI: $10.1016 / \mathrm{j}$.trac.2014.10.011

[28] Twiss, M.R.: Standardized methods are required to assess and manage microplastic contamination of the Great Lakes system, J. Great Lakes Res. 2016, 42(5), 921-925 DOI: 10.1016/j.jglr.2016.07.032

[29] Eriksen, M.; Mason, S.; Wilson, S.; Box, C.; Zellers, A.; Edwards, W. et al.: Microplastic pollution in the surface waters of the Laurentian Great Lakes, Mar. Pollut. Bull. 2013, 77(1-2), 177-182 DOI: 10.1016/j.marpolbul.2013.10.007

[30] Mato, Y.; Isobe, T.; Takada, H.; Kanehiro, H.; Ohtake, C.; Kaminuma, T.: Plastic resin pellets as a transport medium for toxic chemicals in the marine environment, Environ. Sci. Technol. 2001, 35(2), 318-324 DOI: 10.1021/es0010498

[31] Cedervall, T.; Hansson, L.A.; Mattsson, K.: Nanoplastics in the aquatic environment, Environ. Sci. Process. Impacts 2015, 17(10), 1712-1721 DOI: $10.1039 / \mathrm{c} 5 \mathrm{em} 00227 \mathrm{c}$ 
[32] Beckingham, B.; Ghosh, U.: Differential bioavailability of polychlorinated biphenyls associated with environmental particles: Microplastic in comparison to wood, coal and biochar, Environ. Poll. 2017, 220, 150-158 DOI: 10.1016/j.envpol.2016.09.033

[33] Batel, A.; Linti, F.; Scherer, M.; Erdinger, L.; Braunbeck, T.: The transfer of benzo[a]pyrene from microplastics to Artemia nauplii and further to ze- brafish via a trophic food web experiment-CYP1A induction and visual tracking of persistent organic pollutants, Environ. Toxicol. Chem. 2016, 35(7), 1656-1666 DOI: 10.1002/etc.3361

[34] Avio, C.G.; Gorbi, S.; Regoli, F.: Plastics and microplastics in the oceans: From emerging pollutants to emerged threat, Mar. Environ. Res. 2017, 128, 2 11 DOI: 10.1016/j.marenvres.2016.05.012 